IZA DP No. 8519

The Reservation Wage Curve:

Evidence from the UK

Sarah Brown

Karl Taylor

October 2014 


\title{
The Reservation Wage Curve: Evidence from the UK
}

\author{
Sarah Brown \\ University of Sheffield \\ and IZA \\ Karl Taylor \\ University of Sheffield \\ and IZA
}

\section{Discussion Paper No. 8519 \\ October 2014}

\author{
IZA \\ P.O. Box 7240 \\ 53072 Bonn \\ Germany \\ Phone: +49-228-3894-0 \\ Fax: +49-228-3894-180 \\ E-mail: iza@iza.org
}

\begin{abstract}
Any opinions expressed here are those of the author(s) and not those of IZA. Research published in this series may include views on policy, but the institute itself takes no institutional policy positions. The IZA research network is committed to the IZA Guiding Principles of Research Integrity.

The Institute for the Study of Labor (IZA) in Bonn is a local and virtual international research center and a place of communication between science, politics and business. IZA is an independent nonprofit organization supported by Deutsche Post Foundation. The center is associated with the University of Bonn and offers a stimulating research environment through its international network, workshops and conferences, data service, project support, research visits and doctoral program. IZA engages in (i) original and internationally competitive research in all fields of labor economics, (ii) development of policy concepts, and (iii) dissemination of research results and concepts to the interested public.
\end{abstract}

IZA Discussion Papers often represent preliminary work and are circulated to encourage discussion. Citation of such a paper should account for its provisional character. A revised version may be available directly from the author. 
IZA Discussion Paper No. 8519

October 2014

\section{ABSTRACT}

\section{The Reservation Wage Curve: Evidence from the UK}

We investigate the relationship between an individuals' reservation wage, i.e. the lowest wage acceptable in order to enter into employment, and unemployment in the local area district. Largely unexplored in the literature this adds to the work which has examined the association between employee wages and unemployment - the 'wage curve'.

JEL Classification: J64, J31, R23

Keywords: reservation wages, wage curve, unemployment

Corresponding author:

Karl Taylor

Department of Economics

University of Sheffield

9 Mappin Street

Sheffield S1 4DT

United Kingdom

E-mail:k.b.taylor@shef.ac.uk 


\section{Introduction and Background}

Philips (1958) explored the relationship between the change in wages and aggregate unemployment, and found that the rate of change in the nominal wage was inversely related to aggregate unemployment. More recently, Blanchflower and Oswald (1994) have taken a micro-econometric approach and argued that it is the wage level which is directly related to regional unemployment. There is a large body of empirical evidence across a number of countries suggesting that the relationship between the level of market wages and the local unemployment rate is negative and relatively stable, which is commonly known as the 'wage curve'. The focus of the empirical literature to date has been on individuals in employment. In contrast, we analyse the relationship between local labour market competition and the reservation wages of the unemployed, the lowest wage at which an individual is willing to work. For those out of work, we would expect the threshold-wage to induce individuals back into employment to be influenced by local labour market conditions.

\section{Methodology}

Letting $i$ denote the individual $(=1, . . \mathrm{N}), j$ the local authority district (LAD) $(=1, \ldots, \mathrm{J}), t$ time $(=1, \ldots, \mathrm{T})$, the natural logarithm of the reservation wage $r w$ can be modelled against a set of covariates $\boldsymbol{X}$ and the natural logarithm of the local unemployment rate, $U_{j t}$, as follows:

$$
\log \left(r w_{i j t}\right)=\theta_{i}+\boldsymbol{X}_{i j t}^{\prime} \gamma+\pi \log \left(U_{j t}\right)+\varepsilon_{i j t}
$$

This is the typical 'wage curve' specification, Blanchflower and Oswald (1994) and is adopted by Blien et al. (2012) who model the German 'reservation wage curve'. The estimation is usually based on either panel data, hence incorporating an individual fixed effect $\theta_{i}$, or on repeated (pooled) cross sections, so $\theta_{i}=\theta$. The key parameter of interest $\pi$ reflects the unemployment elasticity of the reservation wage. With respect to the market wage curve, where the dependent variable is employee wages, the estimate of $\pi$ is consistently 
found to be negative at approximately -0.1 across different time periods and countries (Blanchflower and Oswald, 2005).

The recent literature has, however, acknowledged shortcomings of the above specification. In particular, the key covariate of interest - unemployment - is observed at a higher level of aggregation than the dependent variable. Hence, the parameter estimate $\hat{\pi}$ will suffer from aggregation bias. Moreover it may be important to adjust wages for individual composition effects. Consequently, following Bell et al. (2002) we estimate the reservation wage curve in two steps. The first stage models reservation wages using a panel fixed effects estimator to control for unobservable time invariant characteristics $\theta_{i}$ :

$\log \left(r w_{i j t}\right)=\theta_{i}+\theta_{j t}+\boldsymbol{X}_{i j t}^{\prime} \gamma+\varepsilon_{i j t}$

The model also includes LAD dummies, $\theta_{j t}$, which can be interpreted as the average reservation wage in the local labour market, corrected for composition effects. In the second stage, reservation wage curves are estimated using the composition corrected reservation wage as the dependent variable:

$\hat{\theta}_{j t}=\beta \hat{\theta}_{j t-1}+\alpha_{j}+\lambda_{t}+\pi_{1} \log \left(U_{j t}\right)+\pi_{2} \log \left(U_{j t-1}\right)+v_{j t}$

To account for reservation wage inertia, the model is dynamic and includes LAD and time fixed effects, denoted by $\alpha_{j}$ and $\lambda_{t}$, respectively. The key covariate of interest is the natural logarithm of unemployment, denoted by $U_{j t}$ which is also included as a lag to allow for possible delays in reservation wages responding to competition in the local labour market.

\section{Data}

We use the British Household Panel Survey (BHPS), a survey conducted by the Institute for Social and Economic Research comprising approximately 10,000 annual individual interviews, from 1991 to 2008. In the BHPS, if the respondent 'is not currently working but has looked for work or has not looked for work in last four weeks but would like a job', he/she is asked: 'What is the lowest weekly take home pay you would consider accepting for a 
job?' Individuals are then asked: 'About how many hours in a week would you expect to have to work for that pay?' From this information we construct hourly reservation wages. We focus upon an unbalanced panel $N T=12,147$ observations over the period 1992 to 2008 which consists of 5,721 individuals. ${ }^{1}$ Around $58 \%$ are typically classified as 'economically inactive'. We include these individuals in the sample if they report a reservation wage since they are arguably signalling labour market attachment (see Blackaby et al., 2007). Figure 1 shows the distribution of the natural logarithm of the hourly reservation wage, which is 1.39 (£4.42), on average, over the period.

Control variables in $\boldsymbol{X}_{i j t}$ include: a quadratic term in the number of years of current labour market state; the natural logarithm of pay in previous/last job; the natural logarithm of household labour income; the natural logarithm of benefit income received by the individual; an index of job search intensity based on the number of different types of search undertaken; aged 16 to 24,25 to 34,35 to 44,45 to 54 , and 55 plus (the omitted category); highest educational qualification distinguishing between degree, teaching or nursing qualification, Advanced (A) level, General Certificate of Secondary Education (GCSE), CSE grades 2-5, any other qualification and no educational attainment (the omitted category); whether currently married or cohabiting; the number of dependent children in the household; whether currently unemployed rather than 'economically inactive'; and binary indicators controlling for the occupation in which a job is sought. In terms of local job market competition, we use $\log$ unemployment defined at the LAD level. There are 278 consistent LADs in the BHPS and we match in gender specific unemployment rates for each LAD over time from the Labour Force Survey.

\footnotetext{
${ }^{1}$ The first year of the BHPS is not used because unemployment data by gender is unavailable at the LAD level.
} 


\section{Results}

The results are shown in Tables 1 (first stage regression) and 2 (the second stage regression). Individual unobserved fixed effects are clearly important in Table 1 given their statistical significance and all of the LAD fixed effects are also statistically significant. The reservation wage is decreasing in the length of the spell of unemployment, consistent with Brown and Taylor (2013) and Krueger and Mueller (2014). The reservation wage is increasing in the pay received in the previous/last job and the level of benefit income received, consistent with previous findings for the UK, e.g. Jones (1989), although both effects are inelastic. Job search is negatively associated with the reservation wage which suggests that individuals who are more informed about the labour market may moderate their wage expectations.

The results of estimating equation (3), the composition adjusted hourly reservation wage, are shown in Table 2, where four specifications are presented: (1) a static model; (2) a static model incorporating lagged unemployment thereby allowing for a possible delay in reservation wages responding to competition in the local labour market; (3) a dynamic model without lagged unemployment; (4) the full specification of equation (3) incorporating dynamics and allowing the reservation wage to be influenced by both contemporaneous and lagged labour market conditions. In each specification, LAD fixed effects are statistically significant as are time specific effects albeit only in the static specifications. Across each specification, the effects of unemployment at the LAD level are statistically significant and negatively associated with the composition adjusted hourly reservation wage with an elasticity of -0.03 in the static model. Including a lag in local area unemployment suggests that, contrary to recent estimates of the wage curve for employees, e.g. Longhi (2012), reservation wage adjustment is contemporaneous.

The final two columns of Table 2 allow for inertia in the reservation wage by incorporating a lagged dependent variable. In both of the dynamic specifications, the effect of 
the lag composition adjusted reservation wage is positive and statistically significant, as is commonly found in modelling the wage curve for employees, e.g. Baltagi et al. (2009), but is relatively small in comparison with a coefficient of approximately 0.1 . Whether the lag of unemployment is included has little effect on the elasticity of the reservation wage with respect to current local area unemployment where the elasticity is around -0.05 . This elasticity is of a similar magnitude to that reported by Blien et al. (2012) for the German reservation wage curve. The corresponding elasticity for the employee wage curve has typically been found to be around -0.1, e.g. Blanchflower and Oswald (2005), but more recent estimates based upon the two-step approach where composition adjusted wages are constructed have suggested an elasticity of around -0.03 in both Germany and the UK, see Baltagi et al. (2009) and Longhi (2012) respectively. Hence, our results suggest that the reservation wage is more sensitive to local labour market conditions in comparison to that of the market wage curve estimates typically found for employed individuals.

\section{Conclusions}

In contrast to the existing literature, we have explored how the reservation wage reacts to local level unemployment rates at a highly disaggregated regional level providing evidence of the existence of a UK 'reservation wage curve.'

\section{References}

Baltagi, B., Blien, U. and K. Wolf (2009) 'New evidence on the dynamic wage curve for Western Germany: 1980-2004.' Labour Economics, 16, 47-51.

Bell, B., Nickell, S. and G. Quintini (2002) 'Wage equations, wage curve and all that.' Labour Economics, 9, 341-360.

Blackaby, D. H., Latreille, P., Murphy, P. D., O'Leary, N. C. and P. J. Sloane (2007) 'An analysis of reservation wages for the economically inactive.' Economic Letters, 97, 1-5.

Blanchflower, D. and A. Oswald (1994) The Wage Curve, MIT Press.

Blanchflower, D. and A. Oswald (2005) The Wage Curve Reloaded. NBER Working Paper, 11338. 
Blien, U., Messmann, S. and M. Trappman (2012) 'Do reservation wages respond to regional unemployment?' IAB Discussion Paper, 22/2012.

Brown, S. and K. Taylor (2013) 'Reservation wages, expected wages and unemployment.' Economics Letters, 119, 276-9.

Jones, S. (1989) 'Reservation wages and the costs of unemployment.' Economica, 56, 22546.

Krueger, A. and A. Mueller (2014) 'A contribution to the empirics of reservation wages.' IZA DP. No. 7957.

Longhi, S. (2012) 'Job competition and the wage curve.' Regional Studies, 46, 611-20.

Phillips, A.W. (1958) 'The relation between unemployment and the rate of change of money wage rates in the United Kingdom, 1861-1957.' Economica, 25, 283-99.

FIGURE 1: Distribution of the log hourly reservation wage

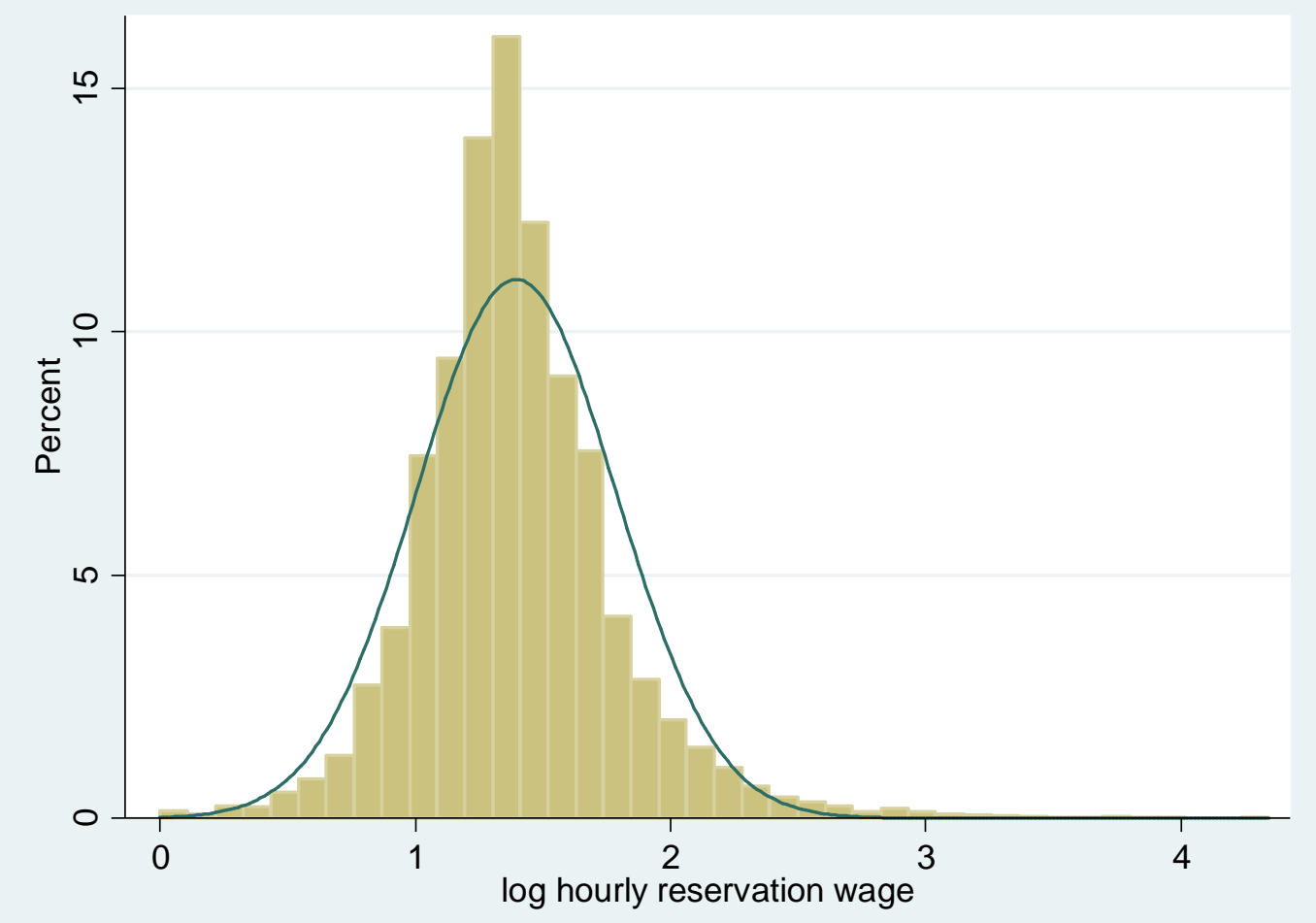


TABLE 1: First stage estimation results full sample; dependent variable $\log \left(r w_{i j t}\right)$

\begin{tabular}{|c|c|c|}
\hline & COEFFICIENTS & T STATISTIC \\
\hline Intercept & 2.5649 & $(3.75)$ \\
\hline Duration of current labour market state & -0.0064 & $(2.01)$ \\
\hline Duration of current labour market state squared & 0.0002 & $(1.79)$ \\
\hline Log pay previous job & 0.0052 & $(2.40)$ \\
\hline Log household labour income & 0.0006 & $(0.30)$ \\
\hline Log benefit income & 0.0068 & $(2.23)$ \\
\hline Index of job search intensity & -0.0101 & $(2.61)$ \\
\hline Whether unemployed & -0.0287 & $(2.05)$ \\
\hline Aged 16-24 & 0.0748 & $(1.10)$ \\
\hline Aged 25-34 & 0.0989 & $(1.73)$ \\
\hline Aged 35-44 & 0.0776 & $(1.66)$ \\
\hline Aged 45-54 & 0.0355 & $(1.06)$ \\
\hline Whether married or cohabiting & 0.0237 & $(1.01)$ \\
\hline Number of dependent children & -0.0074 & $(0.82)$ \\
\hline Degree & 0.1983 & $(2.56)$ \\
\hline Teaching or nursing & 0.0752 & $(1.77)$ \\
\hline A level & 0.0946 & $(1.87)$ \\
\hline GCSE/ O level & 0.0499 & $(1.05)$ \\
\hline CSE & 0.0293 & $(0.39)$ \\
\hline Other qualification & -0.0211 & $(0.25)$ \\
\hline R squared & \multicolumn{2}{|c|}{0.5248} \\
\hline $\mathrm{H}_{0}$ : Individual $\mathrm{FE} \theta_{i}=0 ; \mathrm{F}[5720,3851] ; \mathrm{p}$ value & \multicolumn{2}{|c|}{$2.19 ; p=[0.000]$} \\
\hline $\mathrm{H}_{0}:$ LAD FE $\theta_{j t}=0 ; \mathrm{F}[2492,3851] ; \mathrm{p}$ value & \multicolumn{2}{|c|}{$1.52 ; p=[0.000]$} \\
\hline OBSERVATIONS (NT) & \multicolumn{2}{|c|}{12,147} \\
\hline
\end{tabular}

Note: Other controls include binary indicators for occupation of job sought. 
TABLE 2: Second stage estimation results full sample; dependent variable composition adjusted reservation wage $\hat{\theta}_{j t}$

\begin{tabular}{|c|c|c|c|c|c|c|c|c|}
\hline & \multicolumn{2}{|c|}{$\begin{array}{c}1 \\
\text { STATIC MODEL }\end{array}$} & \multicolumn{2}{|c|}{$\begin{array}{c}2 \\
\text { STATIC MODEL AND } \\
\text { LAGGED UE }\end{array}$} & \multicolumn{2}{|c|}{$\begin{array}{c}3 \\
\text { DYNAMIC MODEL }\end{array}$} & \multicolumn{2}{|c|}{$\begin{array}{c}4 \\
\text { DYNAMIC MODEL AND } \\
\text { LAGGED UE }\end{array}$} \\
\hline & $\mathrm{COEF}$ & T STAT & COEF & T STAT & COEF & T STAT & COEF & T STAT \\
\hline$\hat{\theta}_{j t-1}$ & \multicolumn{2}{|c|}{-} & \multicolumn{2}{|c|}{-} & 0.0966 & $(3.28)$ & 0.0958 & $(3.25)$ \\
\hline $\log \left(U_{j t}\right)$ & -0.0306 & $(2.35)$ & -0.0487 & $(2.24)$ & -0.0501 & $(2.34)$ & -0.0463 & $(2.24)$ \\
\hline $\log \left(U_{j t-1}\right)$ & \multicolumn{2}{|c|}{-} & -0.0275 & $(1.22)$ & \multicolumn{2}{|c|}{-} & -0.0259 & $(1.15)$ \\
\hline R squared & \multicolumn{2}{|c|}{0.8817} & \multicolumn{2}{|c|}{0.9194} & \multicolumn{2}{|c|}{0.9199} & \multicolumn{2}{|c|}{0.9199} \\
\hline AIC (BIC) & \multicolumn{2}{|c|}{$3,031(5,878)$} & \multicolumn{2}{|c|}{$1,541(3,919)$} & \multicolumn{2}{|c|}{$1,530(3,913)$} & \multicolumn{2}{|c|}{$1,529(3,907)$} \\
\hline $\mathrm{H}_{0}: \alpha_{j}=0 ; \mathrm{F}$ statistic; $\mathrm{p}$ value & \multicolumn{2}{|c|}{$20.00 ; p=[0.000]$} & \multicolumn{2}{|c|}{$20.97 ; p=[0.000]$} & \multicolumn{2}{|c|}{$5.45 ; p=[0.000]$} & \multicolumn{2}{|c|}{$5.46 ; p=[0.000]$} \\
\hline $\mathrm{H}_{0}: \lambda_{t}=0 ; \mathrm{F}$ statistic; $\mathrm{p}$ value & \multicolumn{2}{|c|}{$1.97 ; p=[0.011]$} & \multicolumn{2}{|c|}{$1.90 ; p=0[0.016]$} & \multicolumn{2}{|c|}{$1.55 ; p=[0.080]$} & \multicolumn{2}{|c|}{$1.47 ; p=[0.107]$} \\
\hline OBSERVATIONS (JT) & \multicolumn{2}{|c|}{2,492} & \multicolumn{2}{|c|}{1,934} & \multicolumn{2}{|c|}{1,934} & \multicolumn{2}{|c|}{1,934} \\
\hline
\end{tabular}

Note: AIC and BIC refer to the Akaike and Schwarz Bayesian information criteria respectively. 